\title{
Latex agglutination in the diagnosis of meningococcal meningitis
}

\author{
W. P. J. SEVERIN \\ From the Department of Bacteriology, the Laboratory of Hygiene, Municipal University of Amsterdam, \\ Netherlands
}

SYNOPSIS Group-specific polysaccharides of Neisseria meningitidis groups $\mathrm{A}$ and $\mathrm{C}$ have been demonstrated by means of a rapid, sensitive slide agglutination test with latex particles coated with antibodies. In this manner, the diagnosis can be made from the cerebrospinal fluid of patients with meningococcal meningitis caused by serogroups $\mathrm{A}$ or $\mathrm{C}$ even when the culture is negative. The method appears to be more sensitive than countercurrent immunoelectrophoresis and less elaborate.

A number of investigators have tried to find a method of demonstrating soluble meningococcal antigen in the cerebrospinal fluid of patients with meningococcal meningitis. Alexander (1937) and Rake (1933) also used a precipitation test in tubes. Greenwood, Whittle, and Dominic-Rajkonic (1971) elaborated a method of double diffusion in agar gel. The latter method takes 24-48 hours. Robinson and Apicella (1970) could show that group-specific meningococcal polysaccharide carries a negative charge and moves freely in agar gel under the influence of a difference in potential. Countercurrent immunoelectrophoresis appeared to be a good method for the demonstration of small amounts of antigen, and Edwards (1971) was able in this manner to establish the presence of group C antigen in the serum of patients with fatal meningococcal septicaemia. Greenwood et al (1971) likewise used this method and demonstrated the presence of the group-specific antigen in the cerebrospinal fluid of patients with group A meningococcal meningitis. Accordingly, it seems justifiable to conclude that countercurrent immunoelectrophoresis is an adequate method for the diagnosis of meningococcal meningitis of groups $\mathrm{A}$ and $\mathrm{C}$, though it requires special equipment.

The demonstration of soluble polysaccharide antigen in cerebrospinal fluid by means of latex agglutination has been described in the case of a number of microorganisms. Bloomfield, Gordon, and Elmendorf (1963) and Goodman, Kaufman, and Koenig (1971) used this method to demonstrate the antigen of Cryptococcus neoformans, and Newman, Stevens, and Gaafar (1970) succeeded in this demonstration for Haemophilus influenzae. Received for publication 20 October 1972.
In either case, the latex agglutination test proved to be more sensitive than the culture of cerebrospinal fluid.

In the present article, a description is given of a rapid and simple method for the demonstration of soluble polysaccharide in the cerebrospinal fluid of patients with group $\mathbf{A}$ or $\mathbf{C}$ meningococcal meningitis. The results are compared with those of countercurrent immunoelectrophoresis.

\section{Material and Methods \\ CEREBROSPINAL FLUID}

Samples of cerebrospinal fluid were taken from patients with meningococcal meningitis all over the country. These specimens were centrifuged elsewhere, the sediment was used for culture, and the supernatant fluid was submitted to the author's laboratory, together with the isolated culture. The strain was serogrouped and freeze dried and the cerebrospinal fluid was stored at $-20^{\circ} \mathrm{C}$.

Cerebrospinal fluid from patients with meningitis caused by other microorganisms and from patients not suffering from meninigitis were also used.

\section{ANTIMENINGOCOCCAL GLOBULINS}

Group-specific antisera were obtained by injecting rabbits intravenously on three successive days each week with increasing doses of live meningococcal suspensions in saline. On the first occasion the animals were injected with $0.1 \mathrm{ml}$ of a suspension with a turbidity corresponding to the fourth tube in the McFarland series. During the course of four weeks the dosage was increased to $1.0 \mathrm{ml}$ of a sus- 
pension having the consistency of milk. After the third week, test bleedings were carried out weekly. The rabbits were bled to death as soon as the agglutination titre had increased to $1: 160$. This antibody level is reached only after six to eight weeks, and sometimes later. The globulins were precipitated from the serum at half saturation with ammonium sulphate, centrifuged at $600 \mathrm{~g}$ for 30 minutes, resuspended in saline to 1 in 5 of the original volume of serum, and dialysed overnight at $4{ }^{\circ} \mathrm{C}$ against saline. The globulin solutions were stored at $-20^{\circ} \mathrm{C}$.

\section{ATEX}

The suspension of polystyrene latex particles $(0 \cdot 81$ $\mathrm{m} \mu$, Difco) was used unwashed and undiluted and stored at $4^{\circ} \mathrm{C}$.

GLYCINE-BUFFERED SALINE PH $8 \cdot 2$

Glycine, $7 \cdot 3 \mathrm{~g}$, and $10 \mathrm{~g}$ sodium chloride were dissolved in $900 \mathrm{ml}$ distilled water. The $p \mathrm{H}$ was adjusted to 8.2 using $1.0 \mathrm{~N}$ sodium hydroxide, and the final volume was brought to 1 litre.

BOVINE SERUM ALBUMIN

Bovine serum albumin (Povite, Holland) was added to glycine-buffered saline to a final dilution of $0 \cdot 1 \%$ (GBS-BSA).

\section{LATEX SENSITIZATION}

To one part of the optimally reactive dilution of the gamma globulin fraction in glycine-buffered saline an equal amount of latex suspension was added. The mixture was shaken well and allowed to stand in a water bath at $37^{\circ} \mathrm{C}$ for two hours. Subsequently, two parts of glycine-buffered saline and bovine serum albumin were added. This sensitized latex suspension is ready for use and can be stored for at least one year at $4^{\circ} \mathrm{C}$. The optimally reactive dilution of the globulins was $1: 160$. The agglutination titre of the sera from which these globulins were prepared also amounted to $1: 160$, for both group $A$ and group C.

\section{LATEX AGgLUTINATION TEST}

To $0.04 \mathrm{ml}$ cerebrospinal fluid, $0.02 \mathrm{ml}$ sensitized latex was added on a ring slide (Adams Clay, USA). After three minutes' shaking, manually or with an electric rotating apparatus (Arthur H. Thomas Cy, Philadelphia, $\mathrm{Pa}$ ) at $150 \mathrm{rpm}$, the agglutination was read with the naked eye. The results were expressed

\begin{tabular}{|c|c|c|c|c|c|c|c|}
\hline \multicolumn{4}{|l|}{ Group $A$} & \multicolumn{4}{|l|}{ Group $C$} \\
\hline Sample & $L A$ & CCIE & Culture $^{1}$ & Sample & $L A$ & $C C I E$ & Culture \\
\hline 2073 & 128 & $\cdots$ & + & 2070 & 2048 & + & - \\
\hline 2078 & 128 & $\therefore$ & $T$ & 2184 & 1024 & $\therefore \cdots$ & + \\
\hline 2086 & 128 & $\ldots$ & - & 2187 & 8 & Weak & Negative 3 \\
\hline 2094 & 1024 & $\therefore \quad:-$ & $\gamma$ & 2212 & 16 & Weak & .. \\
\hline 2097 & 128 & - & - & 2255 & 512 & $\therefore$ & $\ldots$ \\
\hline 2098 & 2048 & $\ldots$ & $\ldots$ & 2285 & 256 & $\ldots$ & $\ldots$ \\
\hline 2103 & Negative & Not done & - & 2303 & 32 & $\div$ & - \\
\hline 2106 & 128 & $\begin{array}{ll}2 \\
+\end{array}$ & $\therefore$ & 2306 & 32 & $\therefore \div$ & - \\
\hline 2110 & 512 & $\div$ & $\div$ & $2331^{5}$ & 256 & - & + \\
\hline 2117 & 8 & Weak & + & & 16 & $\therefore$ & Negative ${ }^{3}$ \\
\hline 2121 & 8 & Negative & + & & 8 & Negative & Negative $^{3}$ \\
\hline 2128 & 8 & Negative & $\therefore$ & 2354 & 2 & Negative & $\ldots$ \\
\hline 2138 & 4 & Weak & $\therefore$ & 2359 & 32 & - & $\ldots$ \\
\hline 2143 & 4096 & $\therefore \quad-$ & $\div$ & 2388 & 4096 & $\pm \quad:-$ & $\cdots$ \\
\hline 2154 & 128 & $\therefore$ & + & 6844 & 64 & $\div$ & Negative ${ }^{2}$ \\
\hline 2156 & 32 & $\therefore$ & + & & & & \\
\hline 2192 & 4 & Negative & + & & & & \\
\hline 2208 & 256 & $\therefore$ & $\therefore$ & & & & \\
\hline 2237 & 64 & $\therefore$ & + & & & & \\
\hline 2248 & Undiluted & Negative & + & & & & \\
\hline 2304 & 512 & $-\div$ & $\therefore$ & & & & \\
\hline 2339 & Negative & Negative & + & & & & \\
\hline 13851 & 16 & Weak & Negative $^{2}$ & & & & \\
\hline 2364 & 64 & ... & + & & & & \\
\hline 2381 & Undiluted & Negative & $\therefore$ & & & & \\
\hline \multirow[t]{2}{*}{$2397^{4}$} & 512 & $\cdots+$ & + & & & & \\
\hline & 32 & $\therefore$ & Negative $^{3}$ & & & & \\
\hline 2357 & Undiluted & Negative & + & & & & \\
\hline
\end{tabular}

Table I Titres of the latex agglutination $(L A)$ and results of countercurrent immunoelectrophoresis $(C C I E)$ obtained with 4.3 samples of cerebrospinal fluid from patients with meningococcal meningitis group $A$ or $C$

${ }^{1}$ Same group as LA and CCIE

${ }^{2}$ Culture of previously withdrawn CSF also negative

${ }^{3}$ Culture of a previously withdrawn sample of CSF positive

-Two successive days

Three successive days 


\begin{tabular}{llll}
\hline & Group A & Group C & Total \\
\hline $\begin{array}{l}\text { Culture positive } \\
\text { LA positive }\end{array}$ & 24 & 11 & 35 \\
$\begin{array}{l}\text { Culture positive } \\
\text { LA negative }\end{array}$ & 2 & & 2 \\
$\begin{array}{l}\text { Culture negative } \\
\text { LA positive }\end{array}$ & 2 & 4 & 6 \\
\hline
\end{tabular}

Table II Results of culturing and of the latex agglutination test $(L A)$ obtained with 43 samples of cerebrospinal fluid from patients with meningococcal meningitis group $A$ or $C$

${ }^{1}$ In four cases, culture tests with cerebrospinal fluid collected earlier had been positive.

according to a 0-4+ scale of Newman et al (1970). The titre is the reciprocal of the highest dilution of the sample of cerebrospinal fluid that gives an agglutination of $3+$ or $4+$.

COUNTERCURRENT JMMUNOELECTROPHORESIS Use was made of $1 \%$ agar Noble in diethyl barbituric acid buffer at $p \mathrm{H} 8 \cdot 1,0.06 \mathrm{~mol}$ per litre, on slides of $7 \times 7 \mathrm{~cm}, 6 \mathrm{ml}$ per slide; holes with a diameter of $3 \mathrm{~mm}$ were punched at distances of $6 \mathrm{~mm}$. Constant voltage $100 \mathrm{~V}$, duration 60 minutes. Using countercurrent immunoelectrophoresis, all samples of cerebrospinal fluid were examined with anti-A, anti-B, and anti-C serum.

\section{Results}

Thirty-five samples of cerebrospinal fluid gave a positive result in both the culture and the latex agglutination tests (Tables I and II). In two other samples of cerebrospinal fluid with a positive culture (2103 and 2339), no polysaccharide could be demonstrated by means of the latex agglutination test, even after concentration with Lyphogel (Gelman). In six other cases the latex agglutination gave a positive and the culture a negative result: in four of these cases the culture of a previously drawn sample of cerebrospinal fluid had given a positive result.

The serological and bacteriological groups were always in accordance with each other and no crossreactions could be observed.

The latex agglutination titres were high in a number of cases, varying from undiluted to a dilution of $1: 4096$ (Table I). The average titre amounted to $1: 64$. A prozone effect was observed in two cases; in a dilution of 1:10 these samples were highly positive, whereas undiluted they gave only a weak reaction.

The results of the countercurrent immunoelectrophoresis (Table I) showed an approximate parallelism with the latex agglutination titres with one exception (2331). Latex agglutination titres lower than 1:32 corresponded to a weak or negative outcome of countercurrent immunoelectrophoresis; of the 11 latex-positive samples of cerebrospinal fluid with titres of $1: 8$ or lower, eight showed no line on countercurrent immunoelectrophoresis and three were doubtful. With the exception of sample no. 2255, definite $V(++)$ lines on counter-current immunoelectrophoresis could always be observed when the latex agglutionation titres were 1:512 or higher.

The following materials were used to check the specificity: (a) 19 samples of cerebrospinal fluid from patients with meningococcal meningitis group B; (b) 20 samples of cerebrospinal fluid from patients with meningitis caused by other microorganisms: Haemophilus influenzae 5, Streptococcus pneumoniae 6, Escherichia coli 2, Klebsiella pneumoniae 2, Streptococcus pyogenes 1, Proteus sp. 1, Staphylococcus aureus 1, Alkaligenes faecalis 1, Cryptococcus neoformans 1; (c) 20 samples from patients free from symptoms of meningitis. None of these samples gave a positive latex agglutination test. In the countercurrent immunoelectrophoresis, a weak, not serospecific line was seen twice with samples of cerebrospinal fluid of group B; weak lines could be discerned in one of these cases with anti-A, anti-B, and anti-C serum, and in the other case with anti-A and anti-B serum. The remaining samples gave negative results on countercurrent immunoelectrophoresis.

\section{Discussion}

If soluble polysaccharide is present in the cerebrospinal fluid, it is possible by means of the latex agglutination test to make the diagnosis of meningococcal meningitis group $\mathrm{A}$ or group $\mathrm{C}$ a few minutes after the withdrawal of the fluid. Among 43 samples of cerebrospinal fluid there were only two in which no polysaccharide could be demonstrated. These two samples had been collected in a very early stage of the disease. From these 43 samples Neisseria meningitidis was cultured 37 times; in four other cases this had only been possible with samples of cerebrospinal fluid collected earlier, and in two cases the culture test was negative. In the latter two cases (13851 and 6844), Gram-negative diplococci had been observed in the sediment of the cerebrospinal fluid. It can be deduced from cases 2397 and 2331, of which samples of cerebrospinal fluid were received on two and three successive days, respectively, and in which only the first samples gave positive culture tests, that antimicrobial therapy causes a rapid fall in the latex agglutination titre although the test may remain positive for several days. 
With the latex agglutination test varying amounts of polysaccharide were found; the highest titre was 1:4096 and on three occasions the reaction was positive solely with undiluted cerebrospinal fluid. The supernatant of Mueller-Hinton broth cultures of group A and group C, 48 hours old, had titres of $1: 8192$ and $1: 2048$, respectively. Polysaccharides of group $\mathbf{A}$ and group $\mathrm{C}$ proved to be particularly specific; no cross-reactions could be observed. The serological and bacteriological groups were always in accordance with each other.

In the 19 samples of cerebrospinal fluid group B, no polysaccharides were demonstrated with the latex agglutination test. Latex coated with antigroup B-globulin likewise revealed no antigen in the supernatant of a broth culture. This could have been due to the absence of soluble capsular polysaccharide in this group (see Cheever, 1965). Robinson and Apicella (1970) did not succeed in isolating group B antigen. Attempts to obtain latex agglutination with antigenic extract of group B, prepared according to the method of Edwards and Driscoll (1967), were unsuccessful. Gotschlich, Teh Yung Liu, and Artenstein (1969), however, succeeded in isolating a polysaccharide from young group B cultures. They entertained the possibility that the polysaccharide of group B can be readily disintegrated enzymically; this might well apply in vivo too. It is noteworthy that the agglutinability of older cultures with group B antiserum remained good. Furthermore, samples of cerebrospinal fluid from cases of group B meningococcal meningitis did not show any precipitation lines on countercurrent immunoelectrophoresis.

Using the latex agglutination test, the diagnosis was missed in only two early cases. There were nine cases in which no antigen could be demonstrated by means of countercurrent immunoelectrophoresis, while in five other cases the reaction was doubtful. It would appear that for tropical west Africa, where group A predominates and for America, where group $\mathrm{C}$ predominates, and also for other countries where these groups have frequently been isolated from clinical material (Abbott and Graves, 1972), the latex agglutination test constitutes a sensitive and reliable method for a rapid, simple diagnosis of meningococcal meningitis.

My thanks are due to the many colleagues who sent us the strains and cerebrospinal fluid samples.

I am grateful to Professor H. C. Zanen for advice and also to Dr C. E. de Moor for helpful criticism of the text.

\section{References}

Abbott, J. D. and Graves J. F. R. (1972). Serotype and sulphonamide sensitivity of meningococci isolated from 1966 to 1971. J. clin. Path. 25, 528-530.

Alexander, H. E. (1937). Prognostic value of the precipitin test in meningococcus meningitis. J. clin. Invest., 16, 207-211.

Bloomfield, N., Gordon, M. A., and Elmendorf, D. F, Jr. (1963). Detection of Cryptococcus neoformans antigen in body fluids by latex particle agglutination (28586). Proc. Soc. exp. Biol. (N.Y.), 114, 64-67.

Cheever, F. S. (1965). The meningococci. In Bacterial and Mycotic Infections of Man, 4th ed., p. 443, edited by R. J. Dubos and J. G. Hirsch. Lippincott, Philadelphia.

Edwards, E. A. (1971). Immunologic investigations of meningococcal disease, I. Group-specific Neisseria meningitidis antigens present in the serum of patients with fulminant meningococcemia. J. Immunol., 106, 314-317.

Edwards, E. A. and Driscoll W. S. (1967). Group specific hemagglutination test for Neisseria meningitidis antibodies (32593). Proc. Soc. exp. Biol. (N.Y.), 126, 876-879.

Goodman, J. S., Kaufman, L., and Koenig, M. G. (1971). Diagnosis of cryptococcal meningitis: value of immunologic detection of cryptococcal antigen. New Engl. J. Med., 285, 434-436.

Gotschlich, E. C., Teh Yung Liu, and Artenstein, M. S. (1969). Human immunity to the meningococcus, III. Preparation and immunochemical properties of the Group A, Group B, and Group C meningococcal polysaccharides. J. exp. Med., 129, 1349-1365.

Greenwood, B. M., Whittle, H. C. and Olivera Dominic-Rajkovic (1971). Counter-current immunoelectroforesis in the diagnosis of meningococcal infections. Lancet 2, 519-521.

Newman, R. B., Stevens, R. W., and Gaafar, H. A. (1970). Latex agglutination test for the diagnosis of Haemophilus influenzae meningitis. J. Lab. clin. Med., 76, 107-113.

Rake, G. (1933). Studies on meningococcus infection. V. The presence of meningococcus precipitinogens in the cerebrospinal fluid. J. exp. Med., 58, 375-383.

Robinson, J. A., and Apicella, M. A. (1970). Isolation and characterization of Neisseria meningitidis Groups A, C, X, and $Y$ polysaccharide antigens. Infect. Immunol., 1, 8-14. 